\title{
Multi-criteria assessment of the Representative Elementary Watershed approach on the Donga catchment (Benin) using a downward approach of model complexity
}

\author{
N. Varado ${ }^{1,2}$, I. Braud ${ }^{1,3}$, S. Galle ${ }^{1,4}$, M. Le Lay ${ }^{1}$, L. Séguis ${ }^{4,5}$, B. Kamagate ${ }^{5}$, and C. Depraetere ${ }^{1}$ \\ ${ }^{1}$ LTHE (UMR 5564 CNRS, INPG, IRD, UJF), BP 53, 38041 Grenoble Cédex 09, France \\ ${ }^{2}$ Cemagref UR Hydrosystèmes et Bio-Procédés, Parc de Tourvoie, BP 44, 92163 Antony Cédex, France \\ ${ }^{3}$ Cemagref UR Hydrologie-Hydraulique, 3 bis quai Chauveau, 69336 Lyon Cédex 09, France \\ ${ }^{4}$ IRD Benin, 08 BP 841, Cotonou, Benin \\ ${ }^{5}$ Hydrosciences, Maison des Sciences de l'Eau, BP 6450134394 Montpellier Cedex 5, France
}

Received: 4 October 2005 - Published in Hydrol. Earth Syst. Sci. Discuss.: 11 November 2005

Revised: 1 March 2006 - Accepted: 18 May 2006 - Published: 8 June 2006

\begin{abstract}
This study is part of the AMMA - African Multidisciplinary Monsoon Analysis- project and aims at a better understanding and modelling of the Donga catchment $\left(580 \mathrm{~km}^{2}\right.$, Benin) behaviour in order to determine its spatially distributed water balance. For this purpose, we applied the REW concept proposed by Reggiani et al. $(1998,1999)$, which allows the description of the main local processes at the sub-watershed scale. Such distributed hydrological models, which represent hydrological processes at various scales, should be evaluated not only on the discharge at the outlet but also on each of the represented processes and in several points of the catchment. This multi-criteria approach is required in order to assess the global behaviour of hydrological models. We applied such multi-criteria strategy to the Donga catchment $\left(586 \mathrm{~km}^{2}\right)$, in Benin. The work was supported by an observation set up, undertaken since 1998 consisting in a network of 20 rain gauges, an automatic meteorological station, 6 discharge stations and 18 wells.
\end{abstract}

The main goal of this study was to assess the model's ability to reproduce the discharge at the outlet, the water table dynamics in several points of the catchment and the vadose zone dynamics at the sub-catchment scale. We tested two spatial discretisations of increasing resolution. To test the internal structure of the model, we looked at its ability to represent also the discharge at intermediate stations. After adjustment of soil parameters, the model is shown to accurately represent discharge down to a drainage area of $100 \mathrm{~km}^{2}$, whereas poorer simulation is achieved on smaller

Correspondence to: I. Braud

(braud@lyon.cemagref.fr) catchments. We introduced the spatial variability of rainfall by distributing the daily rainfall over the REW and obtained a very low sensitivity of the model response to this variability. Simulation of groundwater levels was poor and our results, in conjunction with new data available at the local scale, suggest that the representation of the processes in the unsaturated zone should first be improved, in order to better simulate soil water dynamics and represent perched water tables which were not included in this first modelling study.

\section{Introduction}

In order to answer questions raised by environmental policies and sustainable development, hydrologists are more and more asked to predict not only the discharge but also other hydrological variables such as water table depth, soil moisture, saturated surface fraction, or water fluxes in various locations within the catchment. Numerous hydrological models have been developed to answer these questions and most of them are expected to become decision tools for watershed management.

Two kinds of modelling approaches are generally proposed and opposed: physically based models and conceptual models. Physically based models rely on the use of plot scale equations. These equations ensure the mass, momentum and energy conservation but require a fine discretisation of the hydrological system. The SHE model (Abbott et al., 1986) is one of the most well-known. It has been improved by coupling a groundwater model to the original SHE model leading to the MIKE-SHE model (Refsgaard et Storm, 1995).

Published by Copernicus GmbH on behalf of the European Geosciences Union. 
Many other distributed and physically based models are used such as the PMRS model (Leavesley and Stannard, 1995) or CATFLOW (Zehe et al., 2001), etc. Many papers discuss the pros and cons of this type of models (Beven, 1989, 1996; Refsgaard and Knudsen, 1996). First, the difficulty to collect physical properties (e.g. soil hydraulic conductivity, vegetation parameters) at the scale of the element grid is often underlined, as well as the poor knowledge of the boundary conditions of the system. The applicability of such models to large catchments is therefore difficult and raises the problem of equifinality in parameters estimation, especially when data for their internal validation are scarce (Grayson et al., 1992).

The alternative to physically based models is the use of conceptual models often based on several reservoirs linked to each other by (semi-)empirical laws. These models can be lumped, e.g. GR4J (Perrin et al., 2003), the SSARR model (Speers, 1995), the TANK model (Sugawara, 1995) but also partially distributed. They are generally valuable for operational water management such as flood forecasting or dam management. Parameters of such models are defined at the catchment scale by calibration but are not easily linked to measured physical properties. Therefore the predictive power of these models is questionable in case of climate or catchment changes and they cannot be easily applied on ungauged catchments.

According to Ambroise (1999), new developing strategies should aim at a combination between the strength of physical models and conceptual ones depending on the processes described, the objectives of the study and the state of knowledge on the catchment. Intermediate approaches should allow a derivation of hydrological variables inside the catchment, but keeping certain thrift in model parameters. This is the case of the REW concept, developed by Reggiani et al. $(1998,1999)$ as an intermediate approach combining the advantages of the usual model types. It rests on global balance laws for mass, momentum and energy formulated at the Representative Elementary Watershed (REW) scale. The strength of the approach is to translate the general problem of model formulation into the derivation of exchange terms between compartments such as the REWs and their zones (saturated, non-saturated, overland, concentrated and river flow), i.e. the closure relations (Reggiani and Schellekens, 2003). The research effort must therefore be concentrated on the formulation of these closure relations (Lee et al., 2005; Zhang and Savenije, 2005) and thus a correct parameterization of the corresponding hydrological fluxes, which is site-specific and scale dependent. In this first step of the Donga catchment modelling, the closure system proposed by Reggiani and Rientjes (2005) has been used.

The study presented in this paper was conducted on the Donga catchment $\left(586 \mathrm{~km}^{2}\right)$ in Benin, West Africa, in the framework of the AMMA (African Monsoon Multidisciplinary Analysis) project. In this region, the impact of rainfall variability on water resources is a crucial question, for scientist but especially for the inhabitants. One of the objectives is therefore to derive the water balance components at various spatial and temporal scales. The modelling exercise presented in this paper was a contribution to this scientific question. When we started this work little was known on the major active processes of the catchment and an experimental set up had been designed to document the various compartments of the water cycle, and is still continuously updated and improved through the collection of new variables. The major role of water, transiting through the groundwater before reaching the river, was suspected but unproven. The use of the REW approach was attractive in this context because it allows the determination of the fluxes between the various hydrological compartments in a distributed manner, with a minimum of data requirement, and includes a representation of the water table.

The main objective of the study was to perform a first assessment of the REW approach to reproduce the catchment behaviour through the simulation and comparison of discharge, piezometric head and soil water content. If so, the model would help to test hypothesis of the catchment behaviour and particularly on the contribution of perched and deep water tables on the production of discharge. If not, improvements of the model structure can be proposed in order to be consistent with the perceptual model of the Donga catchment. Two other objectives were underlying this study: i) illustrate the advantage of building a synergy between observation and modelling in order to progress in the use and validation of distributed hydrological models, and more specifically point out the deficiency in the measurement protocol ii) use the multi-scale formulation of the REW model to get some insight into the following question: which spatial resolution, which complexity in modelled processes are required to which output? Intuitively, it is clear that the answer will be different if we are only interested in discharge at the monthly time scale than if we wish a simulation of discharge, groundwater levels and soil moisture at the daily time scale.

To reach these objectives, we performed a downward evaluation of the model by considering two spatial discretisations and an increasing complexity in the spatial variability of input variables and parameters. In order to assess the model structure, the evaluation of a distributed model representing various processes should be done on each hydrological compartment it represents and at various scales (Refsgaard, 1997; Michaud and Sorooshian; 1994; Bergström et al., 2002; Fortin et al. 2001, Anderton et al. 2002). As a single and integrative variable (i.e. the outlet discharge) is not sufficient to assess an accurate model structure (Michaud and Sorooshian, 1994), a multi-criteria evaluation of the model was then performed in order to represent the discharge at the outlet and at intermediate stations, the groundwater dynamics and the saturation dynamics of soils at the season scale. This evaluation of the model at intermediate stations and on internal state variables helped in testing the internal structure 


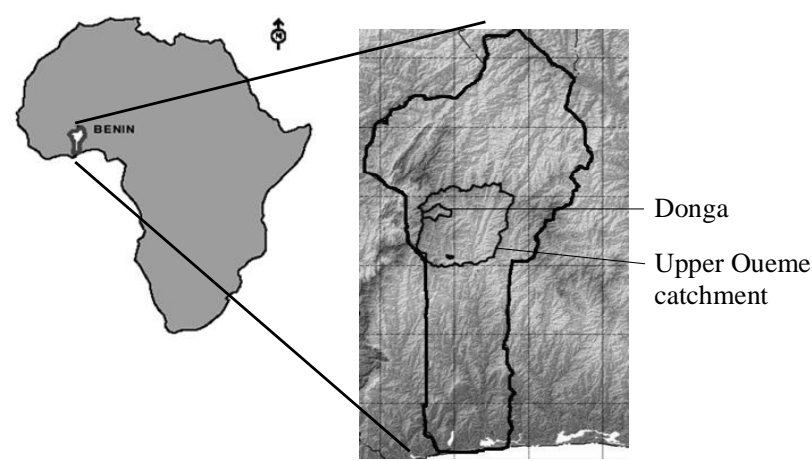

Fig. 1. Situation of the Donga catchment in Benin, Africa.

and complexity of the model. Eventually, the rainfall input was distributed at the catchment scale in order to see if the representation of discharge at every station could be improved by taking into account the spatial variability of rainfall.

\section{Material}

\subsection{The Donga catchment and the AMMA project}

The Donga catchment is part of one of the medium-scale windows of the AMMA project (African Monsoon Multidisciplinary Analysis) that aims at a better understanding of the African Monsoon mechanisms and the interaction between the atmosphere and the continental surface (Lebel et al., 2003). The Upper Oueme catchment in Benin (Fig. 1) has been instrumented since 1997. A special effort has been undertaken in the Donga catchment $\left(586 \mathrm{~km}^{2}\right)$ in order to document processes governing the interaction between the soil and the atmosphere and to be able to close the water budget at a relatively small scale (Séguis et al., 2004). The measurement network, densified in 2002, is well suited for the evaluation of a distributed model representing various processes. In this numerical study with the REW model, we used data from 1998 to 2002. Table 1 summarises the data and the sensors used in the catchment.

The total annual precipitation on the Donga catchment is around $1200 \mathrm{~mm}$ that falls between April and October. Before 2002, 9 rain gauges were available on the catchment (Fig. 2). In 2002, 11 additional rain gauges were installed in order to improve the description of the spatial variability of rainfall at the catchment scale.

An automatic meteorological station was installed on the catchment, in Djougou (see Fig. 2), in 2002. It provides meteorological data at a $15 \mathrm{~min}$ time step: air temperature, air humidity, wind speed, radiation and air pressure. A synoptic station is also available at a $130 \mathrm{~km}$ distance from the catchment, in the city of Parakou. From these data, we calculated a daily Potential EvapoTranspiration (PET) with the

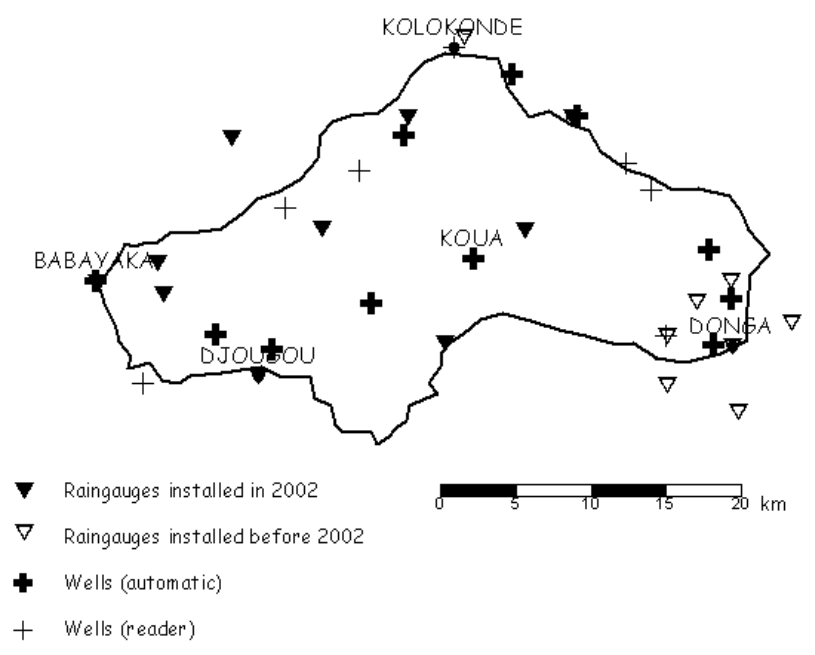

Fig. 2. Network of raingauges and wells on the Donga catchment.

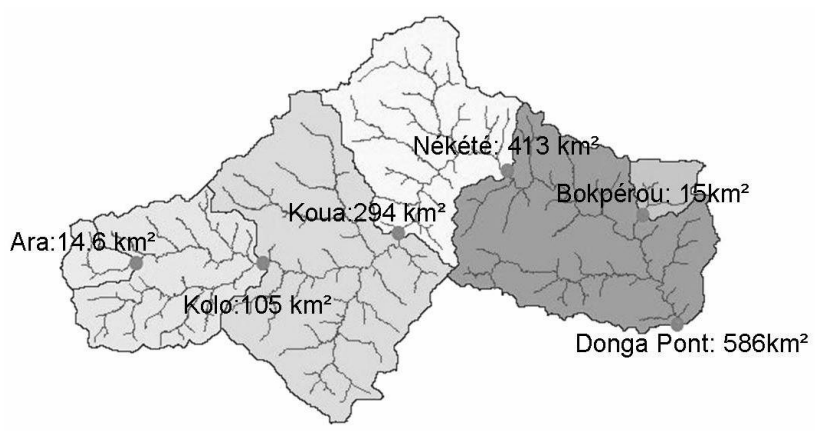

Fig. 3. 6 gauged stations and their drainage area.

FAO method (1998), assumed constant for the whole catchment. The annual PET is about $1600 \mathrm{~mm}$.

The soils are characteristic of the West African soils. The top horizon is a dry alteration of 1 or $2 \mathrm{~m}$ depth. Below, layers of alterites are found down to around 10-20 m depth, less and less altered with depth. The underlying bedrock is fractured with a crack density decreasing with depth. No quantitative data was available for the characterisation of the alterites and the bedrock. Information from previous Sahelian studies (Leduc, personal communication) reports a huge decrease of porosity in the alterite horizons (3-5\%), as compared to the soil surface. The surface layer has been sampled on a $3.5 \mathrm{~km}$ grid (66 sample points) in order to determine the soil hydraulic properties using simple infiltration tests (the Beerkan method, Braud et al., 2005). A pedologic map of the region is also available (Faure, 1977).

Since 1998, discharge data are available at the outlet. In 2002, 5 other stations were installed in order to monitor 5 nested watersheds and 2 small upstream watersheds (Fig. 3). The annual runoff at the outlet varies from $149 \mathrm{~mm}$ in 2002 to $413 \mathrm{~mm}$ in 1998, with respectively a runoff coefficient from 
Table 1. Data and sensors used on the Donga catchment.

\begin{tabular}{|c|c|c|c|c|c|}
\hline Data type & Material & Localisation & $\begin{array}{l}\text { Measure } \\
\text { period }\end{array}$ & Type & Temporal sampling \\
\hline \multirow[t]{6}{*}{$\begin{array}{l}\text { Meteo-rological } \\
\text { data }\end{array}$} & Raingauge & $\begin{array}{l}\text { Donga catch- } \\
\text { ment (Fig. 2) }\end{array}$ & $\begin{array}{l}\text { since } 1998(10) \\
\text { since } 2002(11)\end{array}$ & $\begin{array}{l}\text { Elsyde Edipe (12) } \\
\text { OTT } 250(4) \\
\text { OTT } 1000(5)\end{array}$ & $5 \mathrm{~min}$ \\
\hline & $\begin{array}{l}\text { Air temperature and } \\
\text { humidity sensor }\end{array}$ & Djougou & since 2002 & Vaisal HMP45C & $15 \mathrm{~min}$ \\
\hline & Pyranometer (Rg) & Djougou & since 2002 & Kipp \& Zonen SP-Lite & $15 \min$ \\
\hline & Radiometer (Rn) & Djougou & since 2002 & Kipp \& Zonen NR-Lite & $15 \mathrm{~min}$ \\
\hline & $\begin{array}{l}\text { Wind monitor } \\
\text { (speed and direction) }\end{array}$ & Djougou & since 2002 & Campbell 05103 & $15 \mathrm{~min}$ \\
\hline & Barometer & Djougou & since 2002 & Druck RPT410F & $15 \mathrm{~min}$ \\
\hline \multirow[t]{2}{*}{ Discharge } & $\begin{array}{l}\text { Automatic discharge } \\
\text { gauge }\end{array}$ & Outlet & since 1998 & OTT Thalymedes & 15 min + scrutinize \\
\hline & $\begin{array}{l}\text { Automatic discharge } \\
\text { gauge }\end{array}$ & $\begin{array}{l}\text { Intermediate } \\
\text { stations } \\
\text { (Fig. 3) }\end{array}$ & since 2002 & OTT Thalymedes & 15 min + scrutinize \\
\hline \multirow[t]{2}{*}{ Piezometry } & $\begin{array}{l}\text { Manual record } \\
\text { of wells }\end{array}$ & cf. Fig. 2 & since 1999 & Manual reading (6) & 3 time a day \\
\hline & Automatic recorders & cf. Fig. 2 & since 1999 & OTT Thalymedes (12) & 15 min + scrutinize \\
\hline Soil humidity & $\begin{array}{l}\text { Hydric budget: } \\
\text { tensiometers, soil } \\
\text { humidity and temper- } \\
\text { ature sensors }\end{array}$ & 2 stations & $\begin{array}{l}\text { since } 2003 \\
\text { since } 2004\end{array}$ & $\begin{array}{l}\text { tensiometer: Watermark } \\
\text { Capacitive sensors CS516 }\end{array}$ & hour + scrutinize \\
\hline
\end{tabular}

$15 \%$ to $30 \%$. In terms of precipitation and discharge, the years 1998 and 1999 are rather humid and 2000, 2001 and 2002 are rather dry, compared to historical data of the Upper Oueme river, from 1925 to 1984 (Le Barbé et al., 1993). Table 2 summarises the rainfall and runoff characteristics for the period 1998-2002.

The discharge is not permanent within the year, in any point of the catchment. The discharge at the outlet begins by the end of June, and shows a delay of about 90 days with respect to the beginning of rainfall. The runoff dries up at about the end of October. The 3 months delay shows that the runoff at the catchment scale cannot only come from direct surface runoff but that water should be stored within the soils in various aquifers and be released later.

Understanding the partition between surface runoff and infiltration, and thus assess the contribution of the various aquifers to the streamflow, are some of the objectives of the AMMA project, for the Donga catchment. This study is only a contribution to this general objective.

In 2002, 18 well levels were monitored by automatic Thalymedes (OTT) or readers (Fig. 2). All these wells are used for water supply. Up to now, there is no information on the extracted water volume. As the pumping influences the level measured in the wells, especially during the dry season, the data was used assuming that the highest measure of the day (in the morning, before the first pumping) represents the equilibrium level of the water table.

All these wells are situated within the alterite horizons and are usually situated at a higher elevation than the neighbouring river reach. No measure from a deeper groundwater table was available at the time of our study. However, some piezometers were installed in 2003 in order to monitor the deeper aquifer and will provide additional information on the connection between the various aquifers and thus the generation of streamflow.

In 2004, two local stations of soil moisture measurement were installed in order to close the water budget at small scale: one is located in a forest and the other one in a fallow field. These two stations measure soil water content, soil matrix potential, and soil temperature on the first meter of soil (with six vertical points at 5, 10, 20, 40, 60 and $100 \mathrm{~cm}$ ). Data from the fallow field were used in order to qualitatively assess the variation of soil saturation within the year, simulated by the REW model. These measures do not represent the whole soil profile but according to recent geochemical results (Kamagaté et al. 2004), the first meter of soil plays a major role in the production of discharge, through the saturation excess mechanism.

As shown in this section, the instrumentation of the Donga catchment was particularly well designed to assess the 
Table 2. Rainfall and runoff characteristics at the outlet of the Donga catchment for the period 1998-2002.

\begin{tabular}{lllll}
\hline & $\begin{array}{l}\text { Rainfall in } \\
\text { Djougou }(\mathrm{mm})\end{array}$ & $\begin{array}{l}\text { Mean rainfall on the catchment } \\
\text { (block kriging) }(\mathrm{mm})\end{array}$ & $\begin{array}{l}\text { Annual runoff } \\
(\mathrm{mm})\end{array}$ & $\begin{array}{l}\text { Runoff } \\
\text { coefficient }\end{array}$ \\
\hline $\begin{array}{l}\text { Mean } 1925-1984 \\
1998\end{array}$ & 1336 & & & \\
1999 & 1349 & 1392 & 413 & $30 \%$ \\
2000 & 1373 & 1423 & 345 & $24 \%$ \\
2001 & 1283 & 1071 & 262 & $24 \%$ \\
2002 & 1170 & 1125 & 217 & $19 \%$ \\
\hline
\end{tabular}

performance of a distributed hydrological model on the representation of various hydrological processes and their importance at the catchment scale. In this study, we focus on the discharge at various stations, the groundwater dynamics and the soil moisture dynamics throughout the season, which are the target variables of the simulation.

\subsection{The REW-v4.0 model}

The model used relies on the REW concept developed by Reggiani et al. $(1998,1999)$ and recently illustrated on two catchments by Reggiani and Rientjes (2005), Fenicia et al. (2005) and Zhang et al. (2005). The version of the model used in this study is the one presented in Reggiani and Rientjes (2005); only a brief summary is presented here. The catchment is divided into several Representative Elementary Watersheds (REW). The number of REWs is controlled by the Stralher order used as a threshold. The REWs are partitioned into 5 different zones which are: the river reach $(\mathrm{R}$ Zone), the unsaturated zone (U Zone), the saturated zone (S Zone), the concentrated overland flow zone (C Zone), and the saturated overland flow zone (O Zone). For each of these zones, an averaging procedure yields the mass and momentum balance equations at the REW scale.

Each zone exchanges fluxes with some of the other zones of the same REW. Figure 4 shows the model structure and the interaction, in terms of water fluxes, between the various zones (i.e. the processes represented). The exchanges between REWs take place in the R Zone, via a routing process from the upstream REWs to the downstream REW, and in the S Zone with all the neighbouring REW's S Zone.

For each zone, the mass and momentum conservation equations are written at the centre of gravity of the zone. These equations are shown to have a common and simple form as they are ordinary differential equations (ODE) (Reggiani et al., 1998).

$\frac{d \psi}{d t}=\sum_{i} e_{i}^{\psi}+R+G$

where $\psi$ is the conservative quantity (mass or momentum), $e_{i}^{\psi}$ is an exchange of mass or momentum between the various
Table 3. Prognostic variables of the mass balance and momentum balance equations for each zone.

\begin{tabular}{lll}
\hline Zone & Mass balance & Momentum balance \\
\hline $\mathrm{S}$ & $y^{s}:$ average depth & $v^{s}:$ average velocity \\
$\mathrm{U}$ & $s^{u}:$ average degree of saturation & $v^{u}:$ average velocity \\
$\mathrm{R}$ & $m^{r}:$ average cross section area & $v^{r}:$ average velocity \\
$\mathrm{O}$ & $y^{o}:$ average depth & $v^{o}:$ average velocity \\
$\mathrm{C}$ & $y^{c}:$ average depth & $v^{c}:$ average velocity \\
\hline
\end{tabular}

zones or between the same zone of two neighbouring REWs. $R$ is an exterior supply and $G$ an internal production. The resolution of the ODE by a Runge-Kutta algorithm, allows the determination of an average property (e.g. wetted cross section $m^{r}$, or saturation degree $s^{u}$, water depths $y^{s}, y^{c}$ or $\left.y^{o}\right)$ and the average velocity of water fluxes within each zone (Table 3).

The $e_{i}^{\psi}$ terms of the ODE are the unknowns of the problem. A closure of the system within a single and physically consistent procedure was proposed by Reggiani et al. (1999, 2001) and Reggiani and Rientjes (2005). This procedure has led to a linearized parameterisation of the fluxes.

We emphasize, here, the fact that, in the REW model, the soil is conceptualised as two underlying reservoirs. The unsaturated zone is a homogeneous reservoir characterised by mean soil properties. It is situated above a saturated zone. The bottom boundary is supposed to be impermeable. The limit between the two zones (i.e. the average saturated zone height) is calculated at each time step and can move upwards and downwards.

\section{Method}

A Digital Elevation Model with a $30 \mathrm{~m}$ resolution was available for the Donga catchment discretisation. The TARDEM software (Tarboton, 1997) was used to analyse the DEM and calculate all geometric information needed by the REW 


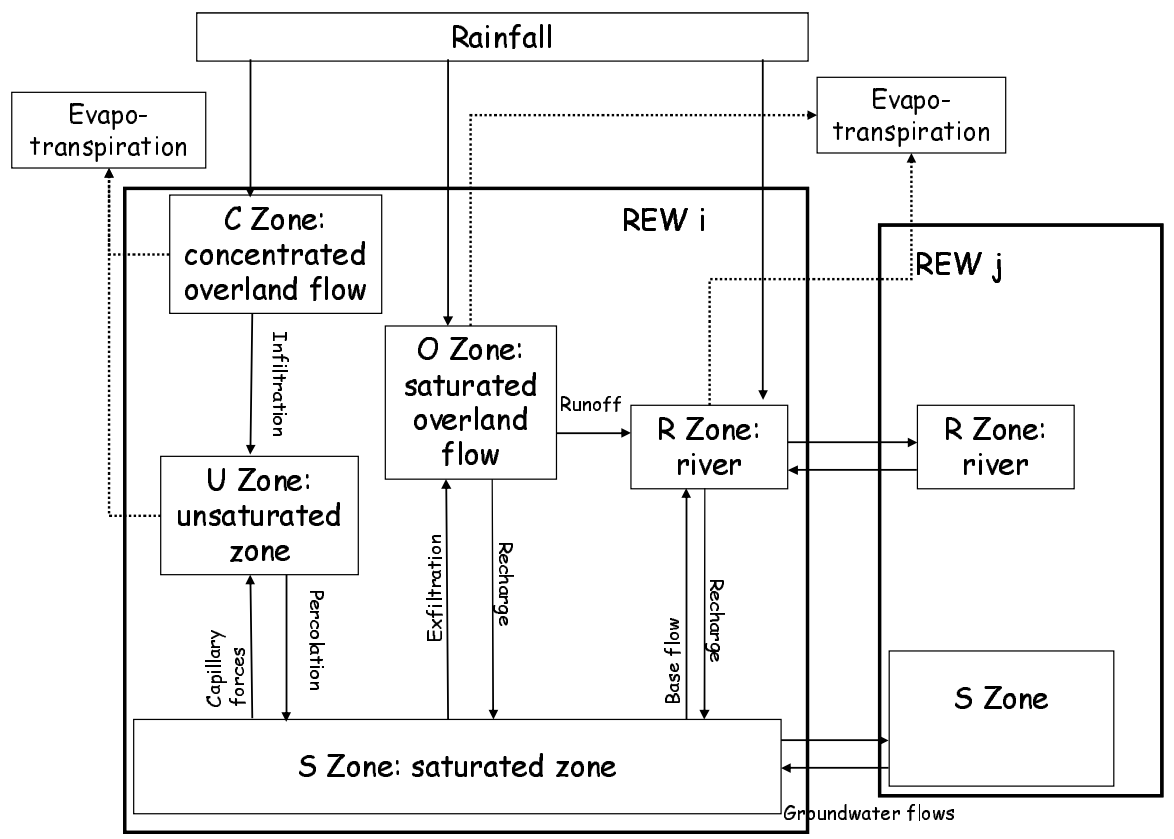

Fig. 4. Schematic structure and exchange fluxes in the REW model.

model (average REW and river reach elevation and slope, river reach length, position of REW centroids, connectivity between REWs, exchange surfaces between REWs, etc.). Two discretisations were used in order to see if one was more accurate for the representation of simulated target variables. 2nd and 3rd Stralher orders led respectively to 117 and 23 REWs (Fig. 5).

Table 4 lists the initial and boundary conditions, and the REW-averaged parameters needed to run the model. The runs started on the 1st January, because initial conditions in terms of discharge and surface runoff are quite well known (zero in any point of the catchment). To exclude the influence of the initial degree of saturation in the unsaturated zone and the initial position of the water table, the simulations were run three times, using final conditions as initial ones when restarting the simulation. Only the third run was used in the analysis of the results.

The soil parameters were taken, first, as uniform and equal to the arithmetic mean of the measured surface values derived from the simplified Beerkan infiltration tests. An attempt of spatialization of the soil properties from the combination of the infiltration measures and the pedologic map was not successful (Varado, 2004) and is not presented here. Hydraulic coefficients for river links and surface were chosen from tables available in the literature (e.g. Chow et al., 1988).

As no information was available for the aquifer boundary conditions, every boundary was supposed to be permeable. The flux at the boundary was calculated directly by the Hardy-Cross algorithm (cf. Reggiani and Rientjes, 2005).
The position of the bedrock was fixed below the mean river bed elevation. Between the two discretisations the total soil volume may change. To avoid this, the bedrock was chosen at the altitude of the river reach with the 3rd Stralher order discretisation and at $8 \mathrm{~m}$ below the river reach with the $2 \mathrm{nd}$ Stralher order discretisation. So, the catchment soil volume remained the same.

A first simulation was run with homogeneous input and homogeneous properties for the whole catchment. In view of the first results, soil parameters were adjusted to improve the model representation of discharge. Then, the rainfall input was distributed between the REWs, in order to see if it allowed a better description of the discharge in several points of the catchment.

We used the efficiency from Nash and Sutcliffe (1970) to assess performance. In order to reduce the weight of large discharge values and to better take into account the effects of strongly reduced runoff during the dry season, the efficiencies were calculated on the square root values (Perrin et al., 2003; Chiew et al., 1993) (Eq. 2). Values were calculated on daily, 10-day average and monthly volumes and discharges:

$E=1-\frac{\sum_{i=1}^{n_{\text {obs }}}\left(\sqrt{Y_{\text {imod }}}-\sqrt{Y_{\text {iobs }}}\right)^{2}}{\sum_{i=1}^{n_{\text {obs }}}\left(\sqrt{Y_{\text {iobs }}}-\sqrt{\overline{Y_{\text {obs }}}}\right)^{2}}$

where $Y_{\text {imod }}$ is the simulated variable, $Y_{\text {iobs }}$ is the observed variable, $\overline{Y_{\mathrm{obs}}}$ is the mean of the observations and $n_{\mathrm{obs}}$ is the number of observations. 

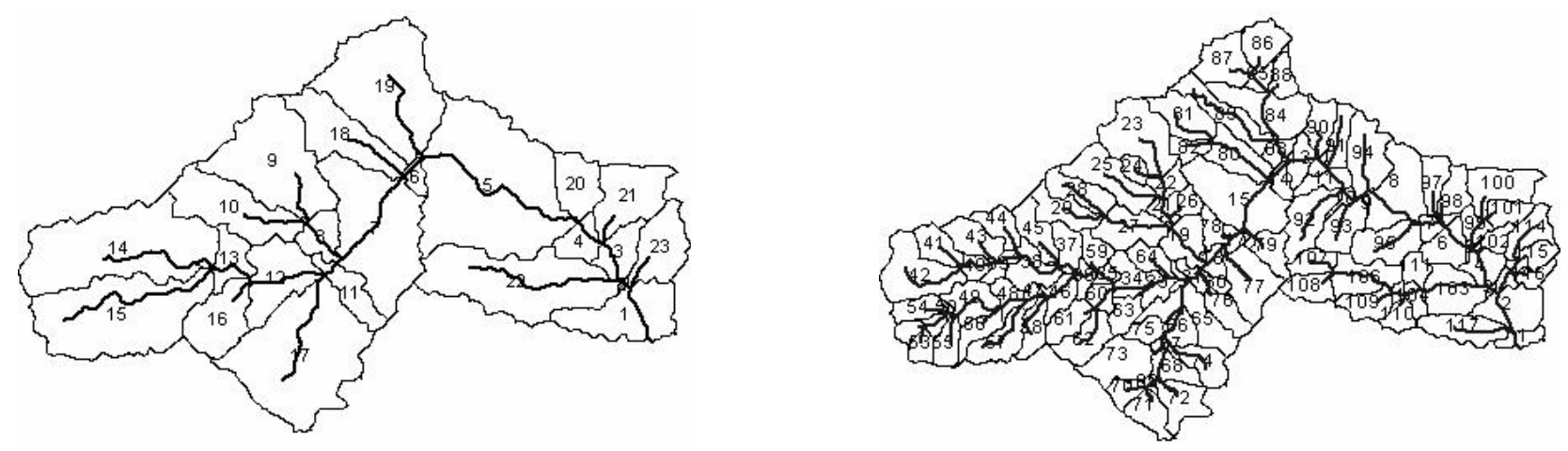

Fig. 5. Two spatial discretisations: 3rd order (23 REWs) and 2nd order (117 REWs).

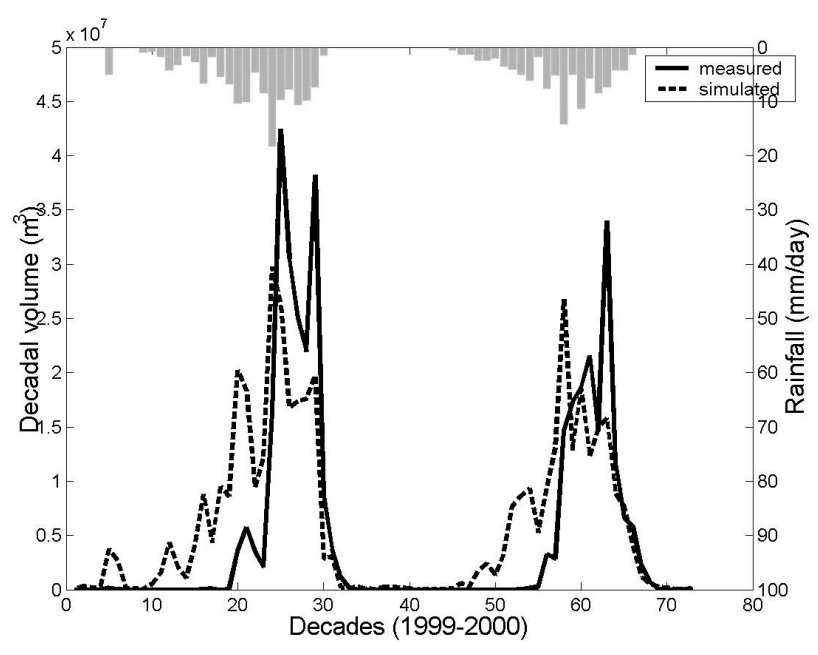

Fig. 6. 10-day average discharge at the outlet in 1999 and 2000, using the mean soil surface parameter, with a 3rd Strahler order discretisation and uniform rainfall.

A qualitative evaluation of the groundwater levels and the soil saturation simulation was also performed and focused on these variables' temporal dynamics.

\section{Results and discussion}

4.1 First application of the REW model using soil surface parameters

The first simulation was performed with the soil parameters from the surface measurements campaign, i.e. without any calibration. The soil parameters $\left(\theta_{s}, K_{s}, \lambda, \eta, h_{e}\right)$ were the same on every REW and equal to the arithmetic mean of the measured values. $\theta_{s}, K_{s}$ were the same for the U Zone and the S Zone.

Figure 6 shows the 10-day average discharge at the outlet for the year 1999 and 2000, with a 3rd Stralher order discretisation. Even if the annual volume was quite accurately

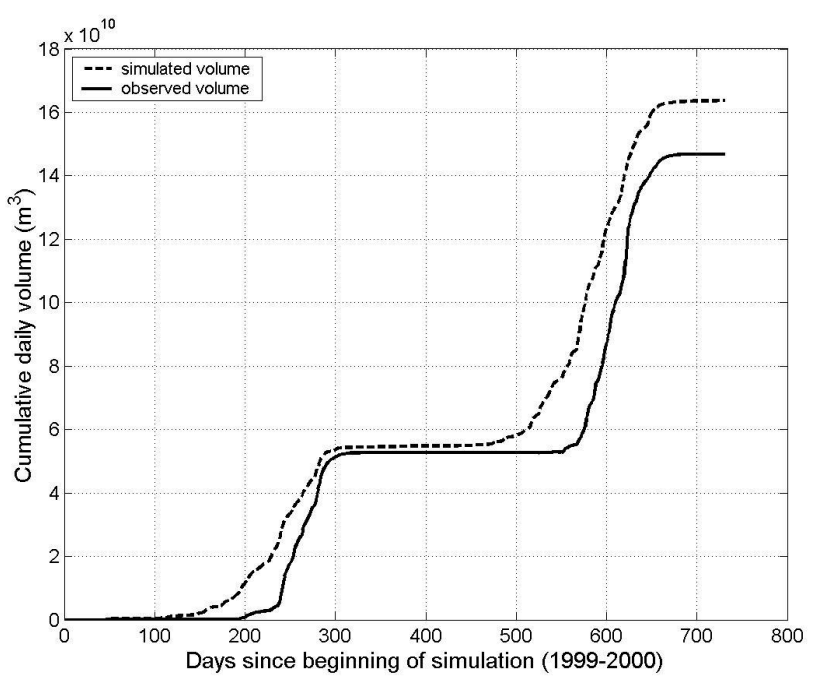

Fig. 7. Cumulative discharge volume at the outlet in 1999 and 2000, using the average soil surface parameters, a 3rd Stralher order discretisation and uniform rainfall.

represented (Fig. 7), two major problems appeared. First, the delay of 3 months between the beginning of the rainfall and the discharge was not reproduced by the model: the model produced discharge as soon as rainfall started. Secondly, at the peak of the rainy season (August, September, and October) the model underestimated the discharge at the outlet. Efficiency on the square root daily discharge was equal to 0.35 and 0.40 on 10-day average discharge. Even if these efficiencies were of the same order of magnitude as the ones presented by Reggiani and Rientjes, (2005), the Donga catchment behaviour seemed not to be captured by the model. Looking at the U Zone and the S Zone, the simulated yearly dynamics (of the degree of saturation and the water level, respectively), were very flat. In the REW-v4.0 model, the rainfall produced direct runoff instead of wetting the soils in the first part of the season. The soils remained dry and the $\mathrm{S}$ zone level remained quite the same, throughout the season. 
Table 4. Input data and parameters needed for the REW-v4.0 model.

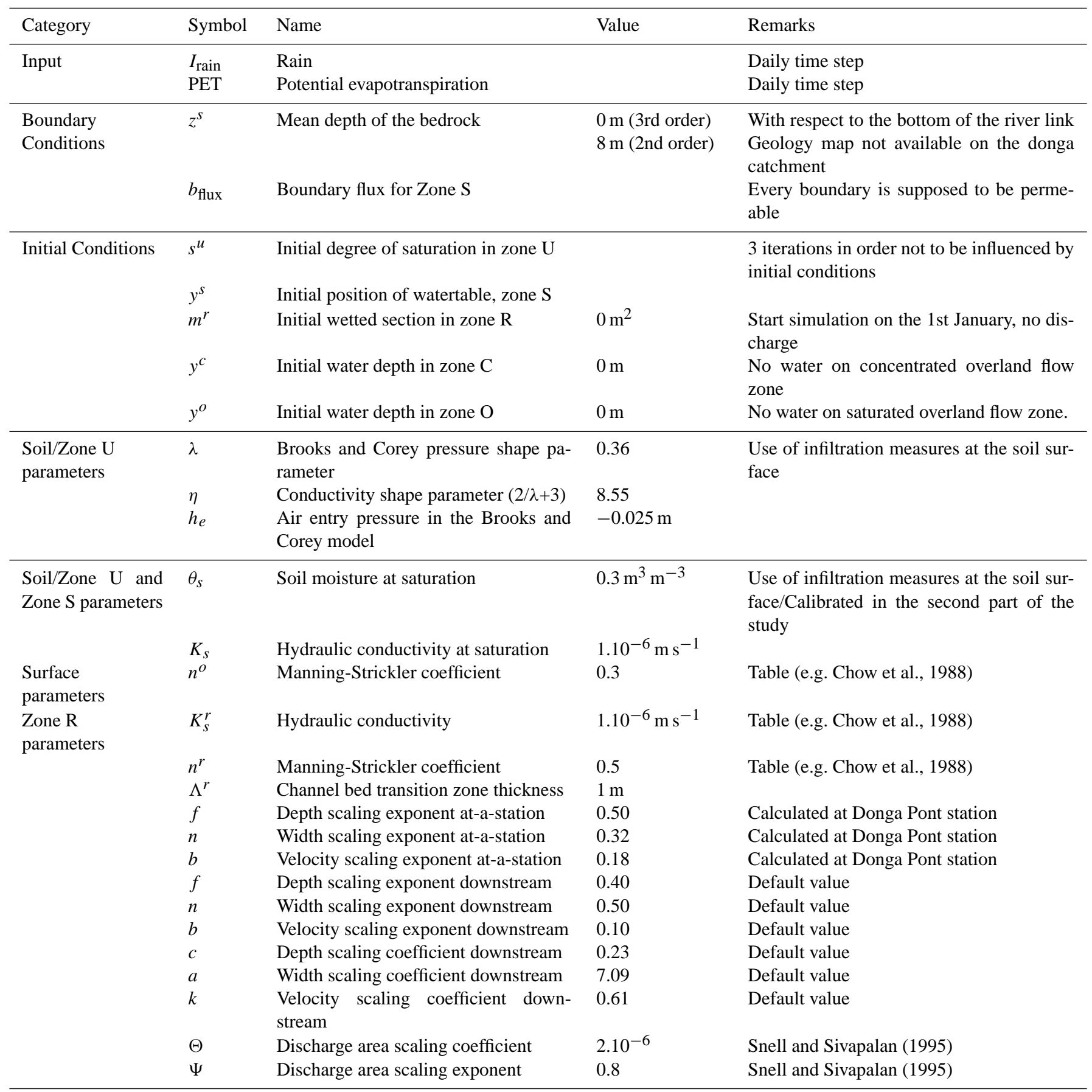

So, the rather poor temporal distribution of the discharge within the season seemed to be caused by a lack of soil infiltration, linked with a problem in the estimation of soil parameters.

\subsection{Calibration}

The soil parameters were determined only for the surface horizon. But one can observe on the Donga catchment a great variation of soil properties (and infiltration capacity) with depth. As the U Zone requires homogeneous parameters, we 
chose to find an equivalent parameter set by means of calibration. The adjustment of $\theta_{s}$ and $K_{s}$ was conducted in order to better represent the discharge at the outlet, especially the 3 months delay in runoff and the peak flow at the peak of the rainy season. The calibration was performed manually at the 3rd and 2nd Stralher order, with $\theta_{s}$ and $K_{s}$ still homogeneous at the catchment scale and identical in the $\mathrm{S}$ Zone and the $\mathrm{U}$ Zone. $K_{s}$ was ranged between $1.10^{-3} \mathrm{~m} \mathrm{~s}^{-1}$ and $1.10^{-7} \mathrm{~m} \mathrm{~s}^{-1}$ with a step of an order of magnitude, refining thereafter. $\theta_{s}$ was ranged between 0.6 and $0.01 \mathrm{~m}^{3} \mathrm{~m}^{-3}$ with a step of 0.1 and then 0.01 for the small values.

We selected 1999 and 2000 as a calibration period, as these two years are respectively rather dry and rather humid. The calibrated values of $K_{S}$ were found not to be identical between order 2 and order 3 (respectively $1.10^{-5} \mathrm{~m} \mathrm{~s}^{-1}$ and $5.10^{-6} \mathrm{~m} \mathrm{~s}^{-1}$ ), suggesting a scale definition of $K_{s}$. The scale definition of $\theta_{s}$ could not be highlighted, because of an identical value of $0.03 \mathrm{~m}^{3} \mathrm{~m}^{-3}$. Reaching two different optimum would probably require to perform the optimization with a step of 0.001 , which was not consistent with the accuracy of $\theta_{s}$. Nevertheless, this very low value (only $10 \%$ of the surface value) was consistent with a huge decrease of porosity with depth and a major role of the alterite horizon as compared to the surface one.

Figure 8 shows the 10-day average volume at the outlet, for the calibration period. The simulated discharges at the beginning of the season (April, May and June) did not perfectly match the observed ones but were largely reduced by the calibration. The rapid reaction of the model to the first rainfall can probably be linked with the saturated fraction area which never decrease below $10 \%$, even in the dry season (see Sect. 4.3.3). Peaks simulation in the peak of the rainy season, was also very much improved. The global efficiency reached 0.63 with a 2 nd order discretisation and only 0.53 with a 3 rd order discretisation. The total runoff volume was deteriorated slightly by the calibration. At the daily time step, the efficiency was also improved with a value of 0.55 and 0.57 respectively with a 2 nd and 3rd order discretisation.

The evaluation period was taken as the whole 1998-2002 period. So, the year 1998, 2001 and 2002 are independent from the calibration period. Table 4 shows for each year the efficiencies calculated on the square root of daily, 10-day average and monthly discharges. The efficiencies were globally as good on the evaluation period (1998, 2001 and 2002) as on the calibration period $(1999,2000)$. The simulation of the year 2002 was less accurate than for the other year, probably because 2002 was the driest year. Looking at the same time step, the efficiencies were higher with a 2 nd order discretisation than with a 3 rd order one. This suggests that a 2 nd order discretisation was more appropriate than a $3 \mathrm{rd}$ one for the simulation of the discharge at the outlet.

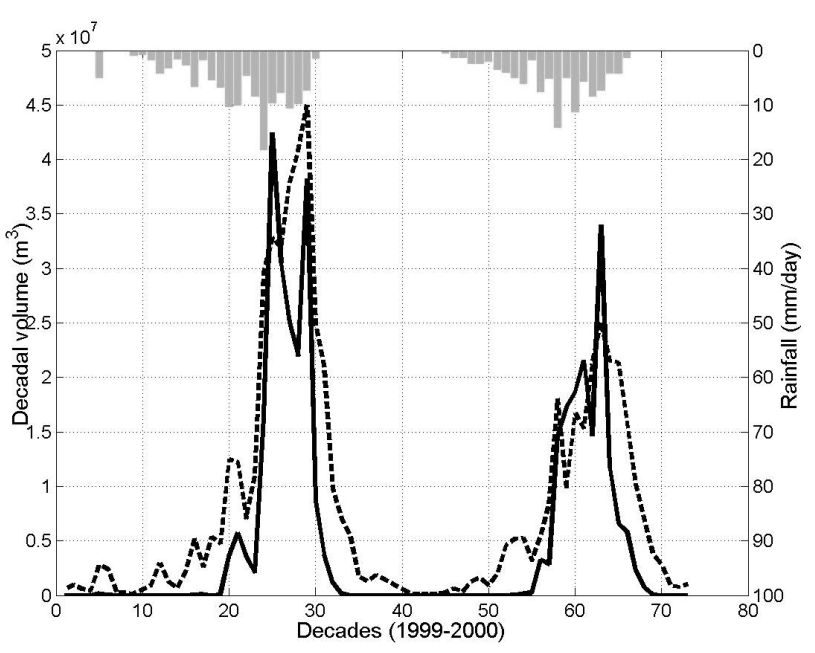

Fig. 8. 10-day average discharge at the outlet for the year 1999 and 2000, after adjusting soil parameters, with a 3rd Stralher order discretisation and uniform rainfall.

\subsection{Effects of the calibration on the internal state variables}

The calibration was performed in order to improve the simulated discharge at the outlet but also with the aim of increasing infiltration in the unsaturated zone and then in the saturated zone.

The comparison between point scale measurements (such as soil water content or groundwater level) and REW-scale averaged values simulated by the model should be made with extreme caution. No evaluation criterion is used here as the comparison is only qualitative and focused on the dynamics of the target variables.

\subsubsection{Soil water content}

Soil water content was not measured during the simulation period and we used the 2004 data to get an idea of the yearly dynamics of the soil water content. As only one station is available up to now, we could not derive an averaged value for a larger scale than the point scale.

The top graph of Fig. 9 shows an example of soil water content changes for the years 1999 and 2000 before the calibration and after the calibration of the soil parameters. Whereas using the surface parameter this degree of saturation never exceeded 0.8 and never decreased below 0.6 , the use of calibrated parameters allowed an almost saturated state at the end of the rainy period (during several weeks in September or October) and a drastic decrease in the dry period (March and April). The bottom graph of Fig. 9 shows the saturation degree measured on the fallow field in 2004 over the first soil meter.

In the REW model the whole U Zone participates to the REW dynamics and the unsaturated depth varies from a few meters to a dozen of meters for this application. Recent 
Simulation 1999-2000

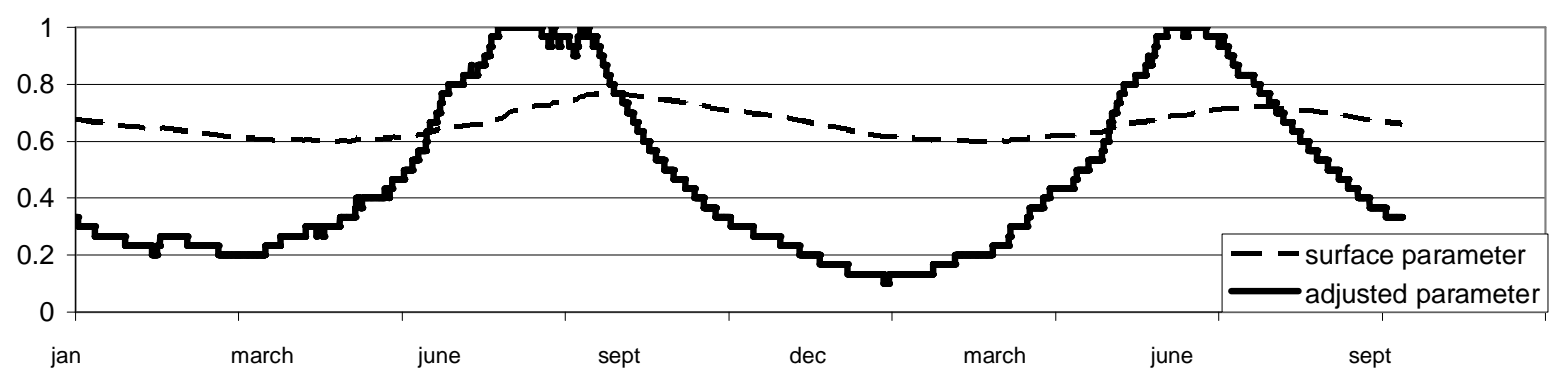

Measures 2004

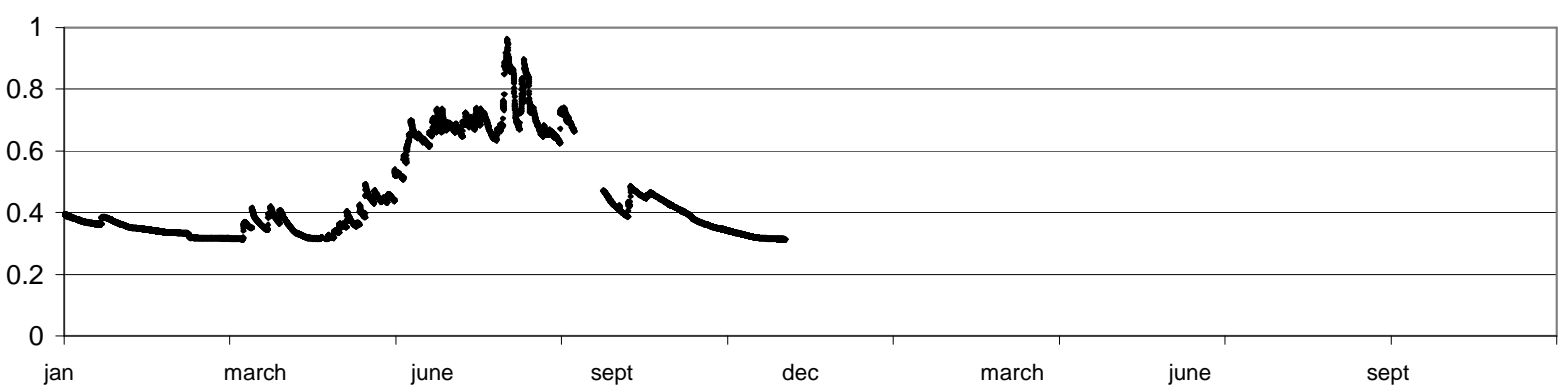

Fig. 9. Variations of soil moisture for the 1999-2000 simulation, using surface parameters or adjusted soil parameters, a 3rd order discretisation and a uniform rainfall. The bottom graph allows the comparison with the soil saturation dynamics calculated from one soil moisture measurement profile down to $1 \mathrm{~m}$, performed in 2004 .

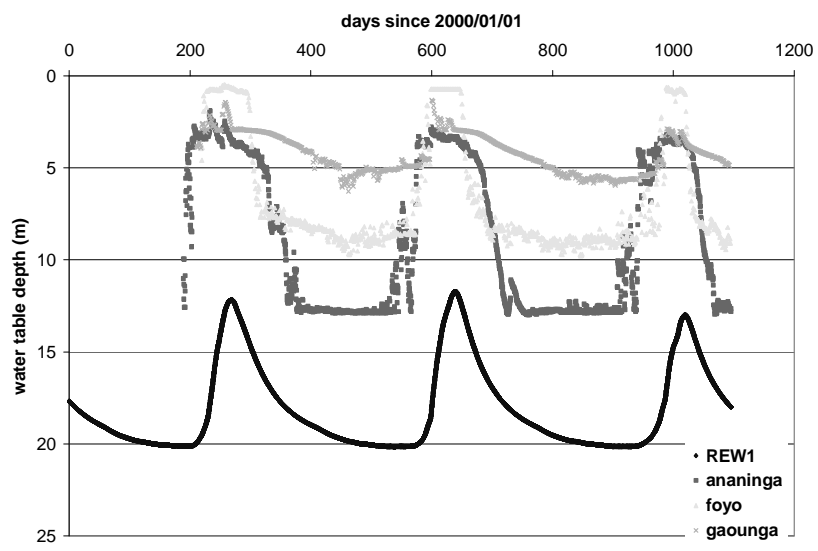

Fig. 10. Comparison of the average calculated groundwater depth of REW no. 1 with the measured depths of three wells located within the same REW. (1998-2002 simulation, 3rd order discretisation, uniform rainfall).

measurements (Séguis et al., 2004) suggest that, on the Donga catchment, the first meter of soil contributes mainly to the streamflow. So, we consider that these measures give an overview of the variation of the degree of saturation in the contributing soil. The comparison of the two graphs in Fig. 9 shows that the use of the calibrated parameters led to a con- sistent simulation of soil saturation, with a variation of about $60 \%$ between the dry and the wet season. This first comparison of soil saturation should be completed as soon as other data are available: additional years, others stations on various land use, and especially averaged soil moisture content from satellite measurements.

\subsubsection{Groundwater level}

The difference of scale between measured and simulated groundwater levels leads to the same problem in the evaluation of the REW model. Whereas observations are discrete in space, the model provides a water table level averaged at the REW scale. Comparison with a single well is not very relevant; but a comparison with various wells situated on a same REW may provide a range of dynamics at the REW scale. At the 3rd Stralher order, 3 wells are located in the REW no. 1: Ananinga, Foyo and Gaounga, which can provide a range of behaviour for this REW. The average surface elevation of REW no. 1 is $343.94 \mathrm{~m}$ a.s.l., whereas the ground surface elevations at the wells locations are respectively $385.67 \mathrm{~m}$, $369.84 \mathrm{~m}, 387.65 \mathrm{~m}$ a.s.l. The average channel elevation of REW no. 1 is $320.60 \mathrm{~m}$ a.s.l. Figure 10 shows the water table depth calculated for the REW no. 1 and the three observed wells for the years 2000, 2001 and 2002. The annual amplitude of the groundwater level was well reproduced by the model ( 8 to $10 \mathrm{~m}$ ). A 4 months delay was simulated between 
the rainfall input and the level rise, i.e. an overestimation of the delay of about 1 month. Whereas the modelled water table was between 12 and $20 \mathrm{~m}$ depth, the observed water table reached the soil surface at the end of the rainy season and was between 10 and $15 \mathrm{~m}$ during the dry season. If we compare the absolute elevation, the difference was worst, as the modelled water table was about 30 to $50 \mathrm{~m}$ deeper than the measured water table.

The wells are drilled in the alterite horizon. A recent geophysical survey reveals that these water tables may be perched water tables, disconnected, not lying on the bedrock and higher than the river bed (Wubda, 2003). Geochemical measurements (Kamagaté et al., 2004) also suggest a major contribution of these perched water tables to the runoff production. Another deeper water table exists but no qualitative data is available at this time of the study. This new information, that were not available at the time the study started, suggests improvement in the description of the soil reservoir and can provide valuable information on its depth throughout the catchment.

In the REW model, the S Zone is a conceptual reservoir for the groundwater storage, which might include both perched and deep water tables. Thus, the simulated groundwater level is a combination of these two entities and might better be seen as the water storage of all the saturated zones. Within the model, no distinction between these two hydrological compartments can be made as the unsaturated zone is also a conceptual and homogeneous reservoir. A way to represent explicitly these perched water tables would be to improve the $\mathrm{U}$ Zone by allowing it to take heterogeneous soils into account. Such a U Zone representation could be based on the module developed by Varado et al. (2006a) based on an efficient and accurate solution of the Richards equation (Ross, 2003).

\subsubsection{Other variables}

The comparison of the exchange fluxes between the various zones of the model showed a major exchange between the saturated surface (zone $\mathrm{O}$ ) and the river (zone $\mathrm{R}$ ) as compared to all other fluxes. This can be seen as a model compensation for the weakness in the unsaturated zone conceptualisation.

Figure 11 shows the time evolution of the fraction of the saturated surface of REW no. 1, before and after the calibration of soil parameters. One can see that this fraction remained the same (around 0.31) throughout the year, before the calibration. After calibration, it varies largely between 0.135 and a maximum at 0.334 (with an average value of 0.20 ), even if it does not decrease to zero. This can not be compared with any measurements because of lack of data, but it is in better agreement with the alternation of a dry and a wet season. Furthermore, the $10 \%$ of the surface always saturated may explain the rapid response of the model to the first rainfall of the season, even after calibration. saturated fraction of the REW surface

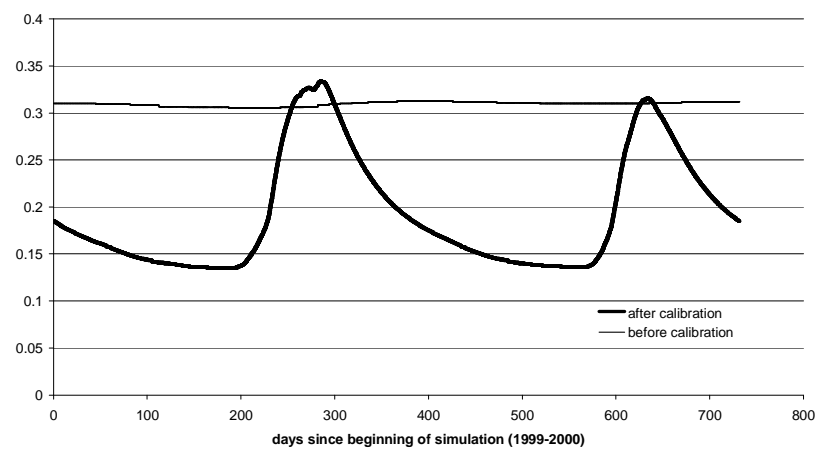

Fig. 11. Comparison of the fraction of saturated surface before and after calibration for REW n0. 1 (1999-2000 simulation, 3rd order discretisation, uniform rainfall).

Table 5. Efficiency for each year, on the square root of daily, 10-day average or monthly discharge, 2 nd and 3rd order.

\begin{tabular}{ccccccc}
\hline & \multicolumn{3}{c}{ 2nd order } & \multicolumn{3}{c}{ 3rd order } \\
\hline & day & 10-day & month & day & 10-day & month \\
\hline 1998 & 0.58 & 0.66 & 0.74 & 0.56 & 0.59 & 0.65 \\
1999 & 0.58 & 0.63 & 0.67 & 0.55 & 0.59 & 0.61 \\
2000 & 0.50 & 0.63 & 0.68 & 0.44 & 0.52 & 0.56 \\
2001 & 0.55 & 0.61 & 0.66 & 0.47 & 0.51 & 0.53 \\
2002 & 0.48 & 0.52 & 0.55 & 0.43 & 0.43 & 0.45 \\
Validation 98-02 & 0.55 & 0.62 & 0.70 & 0.51 & 0.55 & 0.58 \\
\hline
\end{tabular}

The validation of the Donga modelling with three objectives (discharge at the outlet, groundwater dynamics, and moisture content dynamics) allow us to gain some insight into the system representation and identify the hypothesis which have to be reconsidered in future work, especially on the contribution of groundwater to the streamflow. The simulated behaviour throughout the year was rather consistent with the knowledge of the Donga catchment we had at the study time, but new data provided new information that will allow to go a step further in this understanding and formalisation of the catchment behaviour.

\subsection{Representation of intermediate stations}

In 2002, 5 more gauging stations were installed. These new stations allowed us to test the model's ability to reproduce intermediate discharge stations which were not used in the calibration process, and so, to test the model internal structure.

Table 5 shows the efficiency on the square root of daily discharge for every station and each discretisation and Fig. 12 shows the simulated and observed discharge at every station for the 3rd order discretisation. It shows that, globally, the discharge at intermediate stations was fairly simulated and 
Table 6. Efficiency on the square root of daily discharge at every station in 2002, 2nd and 3rd order.

\begin{tabular}{lccc}
\hline Station & Drainage area $\left(\mathrm{km}^{2}\right)$ & 2nd order & 3rd order \\
\hline Ara & 12.8 & 0.45 & 0.14 \\
Bokpérou & 17.4 & 0.21 & 0.26 \\
Route de Kolokondé & 105 & 0.42 & 0.59 \\
Koua & 292 & -3.08 & 0.51 \\
Nékété & 409 & 0.51 & 0.60 \\
Donga_Pont & 586 & 0.48 & 0.43 \\
\hline
\end{tabular}

Table 7. Influence of rainfall distribution on daily, 10-day average and monthly efficiency.

\begin{tabular}{llcc}
\hline Efficiency & rainfall & 2nd order & 3rd order \\
\hline \multirow{2}{*}{ Daily } & distributed & 0.50 & 0.45 \\
& homogeneous & 0.48 & 0.43 \\
\multirow{2}{*}{ 10-day average } & distributed & 0.55 & 0.45 \\
& homogeneous & 0.52 & 0.43 \\
Monthly & distributed & 0.58 & 0.47 \\
& homogeneous & 0.55 & 0.45 \\
\hline
\end{tabular}

that for some stations the efficiency was even higher than at the outlet: Route de Kolokondé, Koua and Nékété stations at the 3rd order, and only Nékété station at the 2nd order.

The two upstream catchments, Ara and Bokpérou, were poorly simulated with both discretisations. The 0.45 value of the efficiency, for the Ara catchment, is misleading because the simulated discharge was too erratic and did not really match the observed discharge. For both stations, the rather large spatial discretisation and temporal scale caused some trouble. A finer discretisation (1st order) may help to better reproduce the processes on these catchments. Furthermore, the response time of these upstream catchments is smaller than the daily time scale used in this study. The model, which used daily rainfall input, was unable to catch the rapid dynamics but would probably be able to, when using hourly or event data.

More generally, up to now, the REW were considered as homogeneous and sub-REW variability was not considered at all. Taking this variability into account may probably help in capturing the catchment dynamics and especially those of the upstream catchments.

To sum up, the REW model was able to simulate the discharge at intermediate stations of the Donga catchment, above a drainage area of about $100 \mathrm{~km}^{2}$. Below this size, the spatial and temporal discretisation and/or the physical mechanisms were not complex enough to well reproduce the discharge, especially on small upstream catchments.
Table 8. Efficiency on the square root of daily discharge at every station in 2002, with and without distribution of precipitation.

\begin{tabular}{lcccc}
\hline & \multicolumn{2}{c}{ 3rd order } & \multicolumn{2}{c}{ ordre2 } \\
\hline & distributed & homogeneous & distributed & homogeneous \\
\hline Donga & 0.45 & 0.43 & 0.50 & 0.48 \\
Ara & 0.16 & 0.14 & 0.44 & 0.45 \\
Bokpérou & 0.23 & 0.26 & 0.22 & 0.21 \\
Kolokondé & 0.60 & 0.59 & 0.42 & 0.42 \\
Koua & 0.51 & 0.51 & -3.08 & -3.08 \\
Nékété & 0.61 & 0.60 & 0.54 & 0.51 \\
\hline
\end{tabular}

\subsection{Spatial distribution of rainfall}

Up to now, the rainfall input was homogeneous at the catchment scale: each REW received the same mean daily rainfall, obtained by block kriging (Delhomme, 1978; VicenteSerrano et al., 2003) over the whole catchment. The 2002 raingauges network allowed a finer description of rainfall by determining a mean daily precipitation with kriging at the REW scale. At the 2nd order, the total annual precipitation on the REWs ranged from $923 \mathrm{~mm}$ to $1191 \mathrm{~mm}$. As compared to the mean annual rainfall obtained at the catchment scale, it represents a decrease of $-9 \%(94 \mathrm{~mm})$ or an increase of $+12 \%$ ( $125 \mathrm{~mm})$, depending on the REW.

For the two discretisations and the year 2002, Table 6 gives the efficiencies at the outlet when considering homogeneous or distributed rainfall. The rainfall distribution slightly improved the efficiencies (for both orders and at every time step), but this improvement is limited to 3 points in efficiency.

Figure 13 shows the 10-day average volumes simulated at the outlet (with a 2nd order discretisation) for the year 2002 when the rainfall is homogeneous or distributed, compared to the observed volumes. The slight improvement seen on the efficiency came from the peak simulation in the peak of the season, even if it was still underestimated. The remaining overestimation of the volumes at the beginning of the season was not reduced by the rainfall distribution.

Table 7 shows the daily efficiency at every station in 2002 . The spatial distribution of rainfall had not a larger influence on discharge at intermediate stations than on discharge at the outlet. The efficiencies were improved by 3 points at most, and some simulations had similar efficiency or were deteriorated by 1 to 3 points. The simulations of the small upstream catchments were not particularly improved.

\section{Discussion and conclusion}

The aim of this first application of the REW concept to the Donga catchment was to test its ability to reproduce the discharge at various points of the catchment, the groundwater dynamics and the variation in soil water content across the 

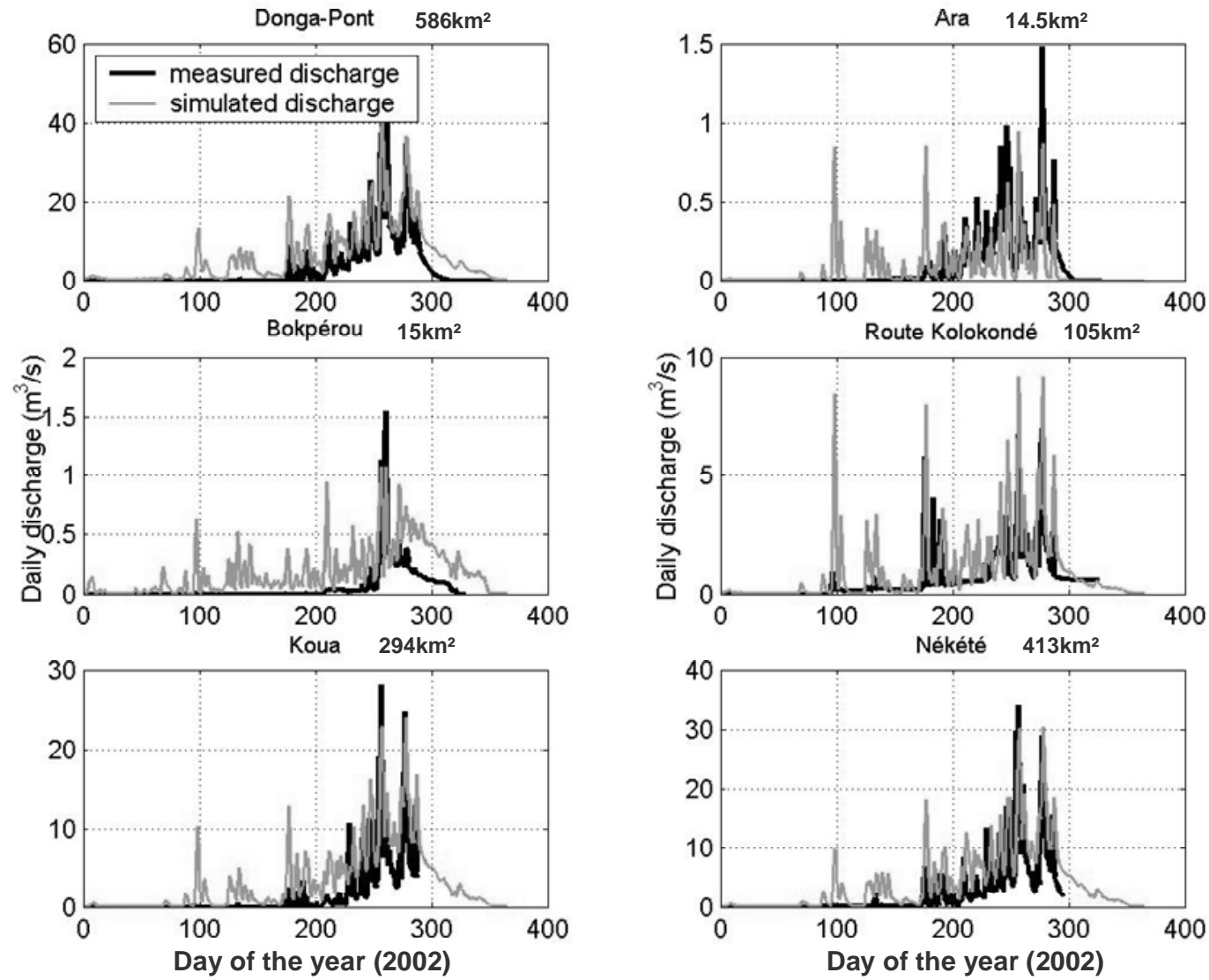

Fig. 12. Simulated and observed daily discharge on the 6 stations for year 2002 (1998-2002 simulation, 3rd order discretisation, uniform rainfall).

season, starting from the hypothesis that deep groundwater was the major contribution to the streamflow. Given the homogeneous nature of the $\mathrm{U}$ and $\mathrm{S}$ Zones, the soil parameters of the model had to be calibrated in order to correctly represent the three months delay between the beginning of the precipitation and the beginning of runoff at the outlet. An optimum of these parameters was found manually. An automatic calibration strategy would be necessary to find a more precise optimum and probably to include more parameters in the calibration strategy.

The need of calibration can be seen as a lack of information concerning the alterite horizon. Nevertheless, this is also linked to the impossibility to represent explicitly the perched water tables with such a conceptualisation of the subsurface, in the REW model: two homogeneous reservoirs, one saturated, the other unsaturated. The necessity to adjust soil parameters to take into account the vertical heterogeneity of the soils pleads for a more realistic simulation of the non-saturated zone dynamics. The geophysical survey (Wubda, 2003) provides a new description of the soil profile that should be incorporated into the model, at medium term. In parallel, the evaluation of the simulated ground-

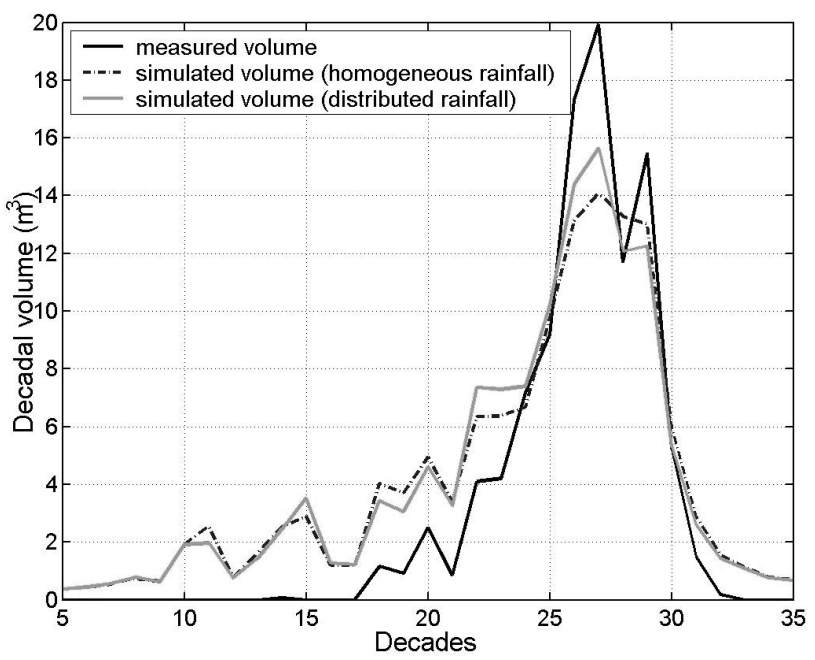

Fig. 13. Comparison of observed and simulated 10-day average volume at the outlet in 2002 with homogeneous or distributed rainfall (1998-2002 simulation, 2nd order discretisation). 
water level has to be tackled by incorporating a distinction between deep groundwater aquifer and perched water tables. These perched water tables seem to play an important role in the discharge production, according to the geochemical measurements (Kamagaté et al., 2004). The inclusion of a more complex vadose zone module (Varado et al. 2006b) into the REW model is then expected to improve not only the simulation of the water table level in the alterite horizon and the soil moisture variations but also the simulation of the discharge at the various stations.

On the Donga catchment, the sub-catchments with a drainage area above $100 \mathrm{~km}^{2}$ are rather well simulated by the REW model. For smaller sub-catchments, the simulated discharge was too erratic. This result suggests that a more physical conceptualisation, a finer spatial discretisation and finer temporal inputs as well as sub-REW variability must be incorporated into the model to better represent the usptream catchments.

The poor improvement of discharge simulation due to the inclusion of the spatial variability of rainfall suggests that the spatial variability of this input was a second order problem with the model conceptualisation used in the study as compared to the fair representation of soil profiles. Nevertheless, more work is probably needed on the quantification of the uncertainty in the rainfall input.

This first hydrological modelling of the Donga catchment showed the interest of a multi-scale and multi-variables instrumentation of the catchment. We also found that model simulations could help in defining a better strategy to monitor the catchment. A strong effort has still to be put on the monitoring/estimation of the evapotranspiration component and its estimation at the catchment scale. In this direction, the planned use of scintillometers could provide an estimation at the small catchment scale of evapotranspiration fluxes, which could be compared with the estimation provided by the model.

Finally, we would like to underline the interest of the REW model formulation: it is rather easy to refine the spatial resolution by considering smaller order river reaches. Furthermore, as the challenge lies in the determination of exchanges fluxes, various levels of complexity for the determination of these fluxes can be tested without modifying the model structure. We will explore this possibility in a next step of the hydrological modelling of this catchment. However, the applicability of this model to semi-arid catchments would probably require a modification of the model's structure. The inclusion of a perched water table zone or an unsaturated zone allowing soil heterogeneity, and a more complex representation of the evapotranspiration processes are ways to be investigated in order to improve the modelling of such a catchment.
Acknowledgements. The authors thank all the scientists that helped in collecting the soil hydraulic properties with the Beerkan method: R. Angulo-Jamarillo, S. Boubkraoui, J.-M. Bouchez, D. De Condappa, G. Derive, A. Gohoun Gossou, R. Haverkamp, P. Reggiani, J. S. Ugalde, and A. Afouda. P. Reggiani is also thanked for providing the version of the REW-v4.0 model used in the study and for his assistance in its use. The work was partly funded by the French National Program /ACI Ecosphère Continentale, PNRH axis. G. Zhang and three anonymous reviewers are thanked for their comments which help improving the quality of the paper.

Edited by: M. Sivapalan

\section{References}

Abbott, M. B., Bathurst, J. C., Cunge, J. A., O'Connell, P. E. and Rasmussen, K., 1986. An introduction to the European Hydrological System - Système Hydrologique Européen, "SHE", 1: History and philosophy of a physically-based distributed modelling system, J. Hydrol., 87(1/2), 45-59.

Ambroise, B.: La dynamique de l'eau dans le bassin versant Processus, Facteurs, Modèles, Edition HGA, Bucarest, 200 pp., 1999.

Anderton, S., Latron, J., White, S. M., Llorens, P., Gallart, F., Salvany, C., and O'Connell, P. E.: Internal evaluation of a physically-based distributed model using data from a Mediterranean mountain catchment, Hydrol. Earth Syst. Sci., 6(1), 6783, 2002.

Bergström, S., Lindström, G., and Pettersson, A.: Multi-variate parameter estimation to increase confidence in hydrological modelling, Hydrol. Processes, 16, 413-421, 2002.

Beven, K. J.: Changing ideas in hydrology - the case of physically based models, J. Hydrol., 105, 157-172, 1989.

Beven, K. J.: A discussion of distributed hydrological modelling, in: Distributed Hydrological Modelling, edited by: Abbott, M. B. and Refsgaard, J. C., Kluwer Academic, pp. 255-278, 1996.

Braud, I., De Condappa, D., Soria, J. M., Haverkamp, R., AnguloJaramillo, R., Galle, S. and Vauclin, M.: Use of scaled forms of the infiltration equation for the estimation of unsaturated soil hydraulic properties (Beerkan method), Europ. J. Soil Sci., 56(3), 361-374, 2005.

Chiew, F. H. S., Stewardson, M. J., and McMahon, T. A. Comparison of six rainfall-runoff modelling approaches, J. Hydrol., 147(1-4), 1-36, 1993.

Chow, V. T., Maidment, D. R., and Mays, L. W.: Applied hydrology, Civil Engineering Series, McGraw-Hill International Edition, 1988.

Delhomme, J. P.: Kriging in the hydrosciences, Adv. Water Resour., 1(5), 251-256, 1978.

FAO: Crop Evaporation - Guidelines for computing crop water requirements, Irrigation and Drainage paper, 56, Rome, 1998.

Faure, P.: Carte pédologique de reconnaissance de la république populaire du Bénin à 1/200000; Feuille de Djougou, ORSTOM, Paris, 58 pp., 1977.

Fenicia, F., Zhang, G. P., Rientjes, T., Hoffmann, L., Pfister, L., and Savenije, H. H. G.: Numerical simulations of runoff generation with surface water-groundwater interactions in the Alzette river alluvial plain (Luxembourg), Phys. Chem. Earth, 30(4-5 SPEC. ISS.), 277-284, 2005. 
Fortin, J.-P., Turcotte, R., Massicotte, S., Moussa, R., Fitzback, J., and Villeneuve, J.-P.: Distributed watershed model compatible with remote sensing and GIS data. 2. Application to Chaudière watershed, J. Hydrologic Engineering, 6(2), 100-108, 2001.

Grayson, R. B., Moore, I. D., and McMahon, T. A.: Physically based hydrologic modeling. 2- Is the concept realistic? Water Resour. Res., 28(10), 2659-2666, 1992.

Kamagate, B., Favreau, G., Séguis, L., Seidel, J.-L., and Le Barbé, L.: Flux nappe-rivière en milieu tropical de socle au Bénin (haut Ouémé), 20è colloque de Géologie Africaine, 2-7 juin 2004, Orléans, France, 2004.

Le Barbé, L., Alé, G., Millet, B., Texier, H., Borel, Y., and Gualde, R.: Les Ressources en eaux superficielles de la République du Bénin. IRD, Collection Monographies Hydrologiques, no. 11, Paris, 469 pp., 1993.

Leavesley, G. H. and Stannard, L. G.: The Precipitation-Runoff Modeling System-PRMS, in: Computer Models of Watershed Hydrology, edited by: Singh, V. P., Water Resources Publications, Highlands Ranch, Colorado, pp. 281-310, 1995.

Lebel, T., Redelsperger, J.-L., and Thorncroft, C.: African Monsoon Multidisciplinary (AMMA): An international research project and field campaign, Exchanges, 27(8), 52-54, 2003.

Lee, H., Sivapalan, M., and Zehe, E.: Representative Elementary Watershed (REW) approach: a new blueprint for hydrological modelling at the catchment scale: development and closure relations, in: Predicting ungauged streamflow in the Mackenzie river basin: today's techniques \& tomorrrow's solutions, edited by: Spence, C., Pomeroy, J., and Pietroniro, A., Canadian Water Resources Association (CWRA), Ottawa, Canada, 2005.

Michaud, J. and Sorooshian, S.: Comparison of simple versus complex distributed runoff models on a midsized semiarid watershed, Water Resour. Res., 30(3), 593-605, 1994.

Nash, J. E. and Sutcliffe, J. V.: River flow forecasting through conceptual models: 1. A discussion of principles, J. Hydrol., 10, 282-290, 1970.

Perrin, C., Michel, C., and Andreassian, V.: Improvement of a parsimonious model for streamflow simulation, J. Hydrol., 279(1-4), 275-289, 2003.

Refsgaard, J. C.: Parametrisation, calibration and validation of distributed hydrological models, J. Hydrol., 198, 69-97, 1997.

Refsgaard, J. C. and Knudsen, J.: Operational validation and intercomparison of different types of hydrological models, Water Resour. Res., 32(7), 2189-2202, 1996.

Refsgaard, J. C. and Storm, B.: MIKE SHE, in: Computer Models of Watershed Hydrology, edited by: Singh, V. P., Water Resources Publications, Highlands Ranch, Colorado, pp. 809-846, 1995.

Reggiani, P., Sivapalan, M., and Hassanizadeh, S. M.: A unifying framework for watershed thermodynamics: balance equations for mass, momentum, energy and entropy, and the second law of thermodynamics, Adv. Water Resour., 22(4), 367-398, 1998.

Reggiani, P., Hassanizadeh, S. M., Sivapalan, M., and Gray, W. G.: A unifying framework for watershed thermodynamics: Constitutive relationships, Adv. Water Resour., 23, 15-39, 1999.

Reggiani, P., Sivapalan, M., Hassanizadeh, S. M., and Gray, W. G.: Coupled equations for mass and momentum balance in a stream network: theoretical derivation and computational experiments, Royal Society Proceedings, 457, pp. 157-189, 2001.
Reggiani, P. and Rientjes, T. H. M.: Flux parameterization in the representative elementary watershed approach: application to a natural basin, Water Resour. Res., 41, W04013, doi:10.1029/2004WR003693, 2005.

Reggiani, P. and Schellekens, J.: Modelling of hydrological responses: the representative elementary watershed approach as an alternative blueprint for watershed modelling, Hydrol. Processes, 17, 3785-3789, 2003.

Ross, P. J.: Modeling soil water and solute transport - Fast, simplified numerical solutions, Agronomy Journal, 95, 1352-1361, 2003.

Séguis, L., Galle, S., Arjounin, M., Boubkraoui, S., Bouchez, J.M., Braud, I., Cazenave, F., Depraetere, C., Gosset, M., Laurent, J.-P., Le Barbé, L., Malinur, F., Cappelaere, B., Favreau, G., Peugeot, C., Seidel, J.-L., Demarez, V., Le Dantec, V., Seghieri, J., Bariac, T., Biron, P., Richards, P., Afouda, A., Descloitres, M., Legchenko, A., Robain, H., Camerlynck, C., Ottlé, C., Zin, I., Zribi, M., Jacquin, F., Kamagate, B., Lawin, E., Le Lay, M., Varado, N. and Zahiri, E. P.: Caractérisation des processus hydrologiques sur le super-site de la Donga, Haut bassin de l'Ouémé (Bénin), ORE AMMA-CATCH, Atelier Expérimentation et Instrumentation. INSU, Paris, 23-24 mars 2004.

Snell, J. and Sivapalan, M.: Application of the meta-channel concept: construction of the meta-channel hydraulic geometry for a natural catchment, in: Scale Issues in Hydrological Modeling, edited by: Kalma, J. D. and Sivapalan, M., John Wiley, Hoboken, N.J., pp. 241-261, 1995.

Speers, D. D.: SSARR Model, in: Computer Models of Watershed Hydrology, edited by: Singh, V. P., Water Resources Publications, Highlands Ranch, Colorado, pp. 367-394, 1995.

Sugawara, M.: Tank Model, in: Computer Models of Watershed Hydrology., edited by: Singh, V. P., Water Resources Publications, Highlands Ranch, Colorado, pp. 165-214, 1995.

Tarboton, D. G.: A new method for the determination of flow directions and contributing areas in grid digital elevation models, Water Resour. Res., 33(2), 309-319, 1997.

Vicente-Serrano, S. M., Saz-Sanchez, M. A., and Cuadrat, J. M.: Comparative analysis of interpolation methods in the middle Ebro Valley (Spain): application to annual precipitation and temperature, Clim. Res., 24(2), 161-180, 2003.

Varado, N.: Contribution au développement d'une modélisation hydrologique distribuée. Application au bassin versant de la Donga, au Bénin, PhD Thesis, Institut National Polytechnique de Grenoble, 310 pp., 2004.

Varado, N., Braud, I., Ross, P. J., and Haverkamp, R.: Assessment of an efficient numerical solution of the Richards equation on bare soil, J. Hydrol.,, 323(1-4), 244-257, 2006 a.

Varado, N., Braud, I., and Ross, P. J.: Development and assessment of an efficient numerical solution of the Richards' equation including root extraction by plants, J. Hydrol., 323(1-4), 258-275, 2006b.

Wubda, M.: Reconnaissance géophysique du bassin versant d'Ara, Mémoire de DESS de Géopysique Appliquée - Université Pierre et Marie Curie, Paris, 2003.

Zehe, E., Maurer, T., Ihringer, J., and Plate, E.: Modeling water flow and mass transport in a loess catchment, Phys. Chem. Earth, Part B: Hydrology, Oceans and Atmosphere, 26(7-8), 487-507, 2001. 
Zhang, G. P., Fenicia, F., Rientjes, T. H. M., Reggiani, P., and Savenije, H. H. G.: Modeling runoff generation in the Geer river basin with improved model parameterizations to the REW approach, Phys. Chem. Earth, 30(4-5 SPEC. ISS.), 285-296, 2005.
Zhang, G. and Savenije, H. H. G.: Rainfall-runoff modelling in a catchment with a complex groundwater flow system: application of the Representative Elementary Watershed (REW) approach, Hydrol. Earth Syst. Sci., 9, 263-278, 2005. 